\title{
Impacts of the Recent Expansion of the Sugarcane Sector on Municipal per Capita Income in São Paulo State
}

\author{
Luiz Satolo and Mirian Bacchi \\ Department of Economics, Management and Sociology, University of São Paulo, Avenida Pádua Dias 11, \\ 13418-900 Piracicaba, SP, Brazil
}

Correspondence should be addressed to Luiz Satolo; luizsatolo@hotmail.com

Received 6 June 2013; Accepted 3 July 2013

Academic Editors: D. Dave, W. R. Reed, and M. Tsionas

Copyright (C) 2013 L. Satolo and M. Bacchi. This is an open access article distributed under the Creative Commons Attribution License, which permits unrestricted use, distribution, and reproduction in any medium, provided the original work is properly cited.

The aim of this study is to evaluate the impacts of this expansion on the income of people in the state's districts and towns. Beginning with a breakdown of the main determinants of per capita income, a spatial dynamic panel model is proposed. The proportion of adults in the municipal population, the labour force utilization rate, and the average labour income were used as control variables. Furthermore, to isolate the impacts of the expansion of the sugarcane sector on per capita gross domestic product (GDP), the share of farming in municipal areas, the share of agriculture within farming in general, the share of sugarcane farming within agriculture, and a dummy for districts and towns with an operational plant were included in the model. The series cover the 645 districts and towns of São Paulo State from 2000 to 2008. The results of the system generalized method of moments (system-GMM) showed a positive relationship of spatial and temporal dependence in the real per capita GDP. And the estimated direct and indirect effects indicate that the expansion of the sugarcane sector had a positive impact on per capita GDP, both in towns where the expansion took place and in their neighbouring towns.

\section{Introduction}

Over the past ten years, there has been a significant growth in sugarcane production in São Paulo State, increasing from almost 2.5 million hectares in 2000 to approximately 4.5 million hectares in 2008 [1]. From 2005 to 2008 alone, the area of harvested sugar cane in the state increased by over 1.8 million hectares, with $53.0 \%$ substituting pasture land and $46.7 \%$ substituting other crops [2].

This expansion was accompanied by increased capacity of preexisting plants and/or distilleries and also more new units throughout the state. According to a primary data survey for this study, the number of towns with an operational industrial plant and/or distillery increased from 109 in 2000 to 143 in 2008.

But this rapid expansion of the sugarcane sector has raised a number of questions concerning its economic, social, and environmental impacts. From a socioeconomic viewpoint, one of the most important aspects to be dealt with is the effect of this growth on income (using the consumer theory, Deaton and Muellbauer [3] show that the level and distribution of per capita income enable an evaluation of social welfare).

In 2008, the GDP of São Paulo State surpassed one trillion reais (or the equivalent to 546 billion dollars), accumulating a real growth of $13.7 \%$ in comparison with 2000 . At the same time, the number of people living in the state rose by almost $9.3 \%$, accounting for a population of 40.4 million habitants in 2008. Consequently, the real per capita GDP of the state rose by $3.7 \%$ between 2000 and 2008, reaching $\$ 13364$ in the final year. However, it is important to point out that the average real municipal per capita GDP in the state saw a growth of 7.9\% during this time, rising from $\$ 7847$ in 2000 to $\$ 8469$ in 2008 .

A pioneer study for evaluating and measuring the socioeconomic impacts of the sugarcane sector on the towns and districts of São Paulo State was conducted by Silva [4]. The model proposed by this author used the municipal human development index (MHDI) as a proxy for socioeconomic conditions, with dummy explanatory variables to denote the presence of the sugarcane sector in the town and control 
variables. However, as the author herself affirms, the results of the study were not conclusive.

Later, other studies sought to evaluate the relationship between the expansion of the sugarcane sector and the economic growth of towns. Walter et al. [5] showed that, in 2000 , towns with plants or significant production of sugarcane (When defining "significant", the authors considered the production of the towns and regions that, in decreasing order, totaled $90 \%$ of the state's production.) had statistically higher per capita income than that of other towns. Spavorek et al. [6], quantifying the effects of a change in how land is used, found that towns involved in the sugarcane sector had higher growth in GDP than other towns. On the other hand, Deuss [7] found no evidence of a causal relationship between the growth of the sugarcane sector and the economy of towns in São Paulo State between 2002 and 2006.

Oliveira [8] compared different socio-economic indicators in the towns of the main sugarcane-producing Brazilian states. Aspects related to education, income distribution, health/longevity, and development in the 1970s, 1980s, 1990s, and 2000s were analyzed. According to the author, there was no evidence that sugarcane resulted in disadvantages from a socio-economic viewpoint. On the contrary, in São Paulo State, all the indicators of the towns with significant sugarcane production were better than those of the control group, with a significance level of $5 \%$.

It is worth emphasizing that none of the aforementioned studies took into account the existence of a possible spatial dependence regarding the phenomenon in question. The pioneer work in this case was that of Chagas et al. [9], which analyzed the impact of the expanding sugarcane sector on the tax revenues of the state's towns using a dynamic panel model with spatial controls.

Since that time, other works seeking to estimate the effect of sugarcane production on regional development have incorporated this spatial component. In Chagas et al. [10], a spatial propensity score matching model was used to estimate the effect of sugarcane production on the MHDI, and the results showed that the presence of the sector is not relevant when it comes to determining social conditions in regions where sugarcane is produced. The same methodology was applied by Chagas et al. [11] to evaluate the effect of sugarcane production on the growth in per capita GDP. In this case, the results showed that the regions which had seen an expansion in sugarcane plantations had also seen a higher growth in per capita GDP than other comparable regions (i.e., in regions where the expansion of sugarcane could have taken place but did not).

Some recent developments in the literature on regional differences and income distribution have pointed out their main determinants. Barros et al. [12] relate the level of per capita income to seven determinants, including demographic dependence, that is, the proportion of adults in the population, the labour utilization rate in economic activities, the average income of work per occupied adult (which in turn is determined by the average bargaining power of the worker, average qualification of the workforce, and quality of jobs), and the income derived from other sources.
Bearing in mind these recent theoretical and methodological developments and seeking to answer some questions in the existing literature, the aim of this study is to evaluate the impacts of the expanding sugarcane sector (taking into account the increased sugarcane plantations and the beginning of operations at new industrial units) on the average income of towns in São Paulo State, which accounted for more than $50 \%$ of the Brazilian sugarcane production and more than one-third of the country's GDP from 2000 to 2008.

Special attention is given to the description of the counterfactual scenarios when interpreting the effects of the sugarcane expansion. This is often not done in other studies, and so, this paper may also provide a useful empirical framework for authors seeking to study similar questions in other contexts.

\section{Modelling per Capita Income to Gauge Variations between Towns in São Paulo State}

The starting point is an adaptation of the model developed by Barros et al. [12] to break down the variations in per capita income into its main determinants. Taken together, these determinants include all the variations in per capita income among towns in São Paulo State over time. For this reason, their inclusion in the model as control variables for dealing with regional differences in the state's economy is strategic when it comes to isolating the effects of the expansion of the sugarcane sector.

Barros et al. [12] propose that per capita income in the family $h, y_{h}$, has only two immediate determinants: the average income per adult, $a_{h}$, and the proportion of adult individuals in the family, $r_{h}$, which may be expressed as

$$
y_{h}=a_{h} r_{h}
$$

Furthermore, the authors regard income per adult in the family $h, a_{h}$, as stemming from three different sources: labour income $\left(l_{h}\right)$, income transfers $\left(t_{h}\right)$, and income from other assets $\left(f_{h}\right)$. This may be expressed as

$$
a_{h}=l_{h}+t_{h}+f_{h} .
$$

However, as the authors point out, it is commonly seen that the major source of family income is labour income. Substituting (1) in (2) results in

$$
y_{h}=\left(l_{h}+t_{h}+f_{h}\right) r_{h}
$$

Meanwhile, labour income per adult in the family $h$, $l_{h}$, can be broken down into two direct determinants: the proportion of working adults, $u_{h}$, and the average labour income of working adults, $w_{h}$. This results in

$$
l_{h}=w_{h} u_{h}
$$

Combining (3) and (4) results in:

$$
\begin{aligned}
y_{h} & =\left(w_{h} u_{h}+t_{h}+f_{h}\right) r_{h} \\
& =w_{h} u_{h} r_{h}+\left(t_{h}+f_{h}\right) r_{h}=w_{h} u_{h} r_{h}+o_{h},
\end{aligned}
$$


where $o_{h}$ is the per capita income share from nonlabour sources.

However, in the simplified version of the model, the authors accept that nonlabour income is negligible in comparison with labour income, that is, $o_{h}=0$. Thus, a function $\varphi$ can be estimated so that

$$
y_{h}=\varphi\left(w_{h}, u_{h}, r_{h}\right)
$$

The authors also claim that the relationships in (6) can be extrapolated to evaluate the per capita income of a group of families in a given region or country providing that the variables used are duly weighted. Thus, the function $\varphi$ can be redefined at the municipal level:

$$
y_{i}=\varphi\left(w_{i}, u_{i}, r_{i}\right) \text {, }
$$

and, in this case, the per capita income of the town $i, y_{i}$, is expressed as a function of the average labour income per worker $\left(w_{i}\right)$, the labour workforce utilization rate $\left(u_{i}\right)$, and the proportion of adults in the municipal population $\left(r_{i}\right)$.

In addition to the variables shown above, the average labour income per worker in agriculture $\left(w_{i}^{A}\right)$ and the labour workforce utilization rate in agriculture $\left(u_{i}^{A}\right)$ will also be used as explanatory variables in the model. Together, $w_{i}$, $w_{i}^{A}, u_{i}, u_{i}^{A}$, and $r_{i}$ will act as controls for diverse socioeconomic and demographic aspects that may also influence the municipal per capita nonlabour income share $\left(o_{i}\right)$. For instance, the relative difference between the total labour utilization rate $\left(u_{i}\right)$ and its equivalent in agriculture $\left(u_{i}^{A}\right)$ can be viewed as a proxy for the difference in the degree of urbanization of a town. Meanwhile, the differences in the economic composition of towns are handled simultaneously by the relative differences between $u_{i}$ and $u_{i}^{A}$ and between $w_{i}$ and $w_{i}^{A}$. Higher levels of schooling and government transfers reflect on relatively higher levels of average income which, in turn, also imply in better access to healthcare and education.

In order to isolate the impact of the sugarcane sector on the average per capita income of towns in São Paulo State, another four variables have been added to the model:

(i) $s^{f}$ : share (\%) of the entire area of the district or town taken up by farming (agriculture, planted forests, and pasture);

(ii) $s_{f}^{a}$ : share (\%) of the area given over to agriculture (temporary and permanent crops) in the farmland of the district;

(iii) $s_{a}^{c}$ : share (\%) of the planted area given over to sugarcane in the agricultural land;

(iv) $D^{U}$ : dummy variable with an assumed value of 1 when the town has an operational plant and/or distillery during the year in question.

In the reduced form, the estimation model proposed in this study is

$$
y_{i}=\varphi\left(w_{i}, w_{i}^{A}, u_{i}, u_{i}^{A}, r_{i}, s_{i}^{f}, s_{f_{i}}^{a}, s_{a i}^{c}, D_{i}^{U}\right) .
$$

\section{Data}

The per capita GDP (used as a proxy for per capita income), average labour income (total and in agriculture), proportion of adults in the population, and the number of jobs (total and in agriculture, used to estimate labour utilization) of all towns in São Paulo State from 2000 to 2008 were obtained from State System Foundation for Data Analysis (in Portuguese, Fundação Sistema Estadual de Análise de Dados (SEADE) [13]).

Both the per capita GDP and labour income were deflated using a centred general price index, the IGP-DI, obtained from IPEADATA [14].

The total cultivated area of sugarcane and the total agricultural area of each town were obtained from the Brazilian Institute of Geography and Statistics (in Portuguese, Instituto Brasileiro de Geografia e Estatística (IBGE) [1]). The area of planted forests (eucalyptus and pine) and the area of pasture were obtained from the Farming Economy Institute (in Portuguese, Instituto de Economia Agrícola (IEA) [15]).

The primary data regarding which plants were in operation between 2000 and 2008 were obtained from various sources, including the Daily Federal Bulletins (in Portuguese, Diário Oficial da União (DOU)), websites of plants and distilleries, the Ministry of Agriculture, Livestock and Supplies (in Portuguese, Ministério da Agricultura, Pecuária e Abastecimento (MAPA)) and the Union of Bioenergy Producers (in Portuguese, União dos Produtores de Bioenergia (UDOP)).

\section{Methodology}

Kukenova and Monteiro [16] explain that, in a spatial context, the main argument in favour of using an extended version of the system-GMM is the fact that this estimator, in addition to controlling the specific effects that do not vary in time and handling the potentially endogenous explanatory variables, also corrects the endogeneity of spatially lagged dependent variables.

4.1. Definition of the Spatial Weights Matrix and Specification of the Spatial Dynamic Panel Model. The criterion for contiguity adopted for this study is that of the fifteen closest towns. In this case, with $d_{i j}$ as the Euclidian distance between each pair of observations $i$ and $j$, the $W_{i, j}$ element of the spatial weight matrix has a value of 1 when

$$
d_{i j} \leq d_{\max i}, \quad i \neq j,
$$

where $d_{\max i}$ is the distance between the $i$ th observation and its 15 th closest neighbour; in the other cases, $W_{i, j}$ has a value of 0 . Moreover, to avoid an observation being used to explain itself, when $i=j \rightarrow W_{i, i}=0$ [17].

Elhorst [18] compared the different specifications of models that had already been used in the literature to analyze the dynamic of the variables in time and space. One of the less restrictive specifications and which, at the same time, satisfies the aims of this study may be expressed as

$$
Y_{t}=\tau Y_{t-1}+\delta W Y_{t}+X_{t}^{\mathrm{exo}} \beta_{1}+W X_{t}^{\mathrm{exo}} \beta_{2}+X_{t}^{\mathrm{endo}} \theta+Z+\varepsilon_{t},
$$


where $Y_{t}$ is an $N \times 1$ vector composed of observations of the dependent variable in each spatial unit $(i=1,2, \ldots, N)$ in the year $t(t=1,2, \ldots, T), X_{t}^{\text {exo }}$ is an $N \times K$ matrix of the exogenous variables, $X_{t}^{\text {endo }}$ is an $N \times L$ matrix of the endogenous variables, $Z$ is the $N \times 1$ vector containing the specific spatial effects that do not vary over time, and $\varepsilon_{t}$ is the error term.

The stationarity condition for a spatial dynamic panel model in the form of (10) may be expressed as [18-20]

$$
\begin{aligned}
& -1+\delta \omega_{\max }<\tau<+1-\delta \omega_{\max }, \quad \text { se } \delta \geq 0 \\
& -1+\delta \omega_{\min }<\tau<+1-\delta \omega_{\min },
\end{aligned}
$$

where $\omega_{\min }$ and $\omega_{\max }$ are, respectively, the minor and major noncomplex characteristic roots of the matrix $\left(I_{N}-\delta W\right)^{-1}\left(\tau I_{N}\right)$.

4.2. Interpretation of Results. According to Debarsy et al. [21], spatial dynamic panel models produce a situation where a variation of the $j$ th observation of the $k$ th explanatory variable in time period $t$ will result in contemporaneous and future responses of the dependent variable in all regions. This occurs due to the presence of a time lag term $\left(y_{j, t-1}\right.$, which captures the temporal dependence), a spatial time lag term $\left(W^{*} y_{j, t}\right.$, which considers spatial dependence), and a crossproduct term $\left(W^{*} x_{j, t}\right.$, which reflects the diffusion of the phenomenon under study in time and space).

In this type of analysis, the focus when interpreting results should be on the effects of the partial derivatives associated with the alteration of explanatory variables. For example, $\partial y_{j t} / \partial x_{j t}^{k}$ is the direct contemporary, that is, short-term effect of an alteration in the $k$-th explanatory variable of region $j$ on the dependent variable of the own region. But there is also a cross-partial derivative, $\partial y_{i t} / \partial x_{j t}^{k}$ which measures the effect of the spatial spillover (designation used for the contemporaneous indirect effect) in region $i, i \neq j$.

In addition to the contemporaneous effects, the spatial dynamic panel model makes it possible to calculate the partial derivatives that quantify the responses of each region and alterations in the explanatory variables of period $t$ considering different time horizons $t+T$. The $T$ periods ahead response of the dependent variable in region $j$ to variations of the $k$ th explanatory variable of the own region is measured by $\partial y_{j, t+T} / \partial x_{j t}^{k}$. And the diffusion effect, which reflects the impact of an alteration of the explanatory variable in region $j$ on the dependent variable of other regions over space and time, is measured by $\partial y_{i, t+T} / \partial x_{j t}^{k}$.

Debarsy et al. [21] derived the general expression for the $T$ period-ahead cumulative impact of a permanent alteration of the $k$ th variable in period $t$. Taking into account the difference between the specification of the model estimated by the authors and the model used in this study (Debarsy et al. [21] define the general expression of cross-partial derivatives using the extended Durbin model. To make it compatible with the specification of the spatial dynamic panel model used in this study, it is necessary to impose a restriction that the parameter of $W Y_{t-1}$ equals zero on the general expression developed by the authors.), the expression that represents the cumulative impact of a permanent variation is such that

$$
\frac{\partial Y_{t+T}}{\partial X^{k^{\prime}}}=\sum_{s=0}^{T} D_{s}\left[I_{N} \beta_{1 k}+W \beta_{2 k}\right],
$$

where $X^{k}$ denotes the $k$ th column of matrix $X(N T \times K), \beta_{1 k}$ and $\beta_{2 k}$ are the defined parameters for variable $k$ in (10) and

$$
D_{s}=(-1)^{s}\left[\left(I_{N}-\delta W\right)^{-1}\left(-\tau I_{N}\right)\right]^{s}\left(I_{N}-\delta W\right)^{-1} .
$$

The main diagonal elements of the sum of matrixes $N \times N$ in (12) to time-horizon $T$ represent the observed impacts from changes in the explanatory variable of the own region that spread and continue to affect the dependent variable in the future due to the existence of spatial and temporal dependence. The sum of the elements of these matrixes outside of the main diagonal measures the spillovers (contemporaneous cross-partial derivatives) and diffusions (cross-partial derivatives in different time periods).

\section{Results}

There now follow the series used in the model estimate. Table 1 shows some descriptive statistics of the continuous variables, that is, municipal and spatially lagged real per capita GDP (Typically, $W^{*}$ is the row-normalized matrix of spatial weights, and, in this case, $W^{*} y$ is the mean of $y$ in neighboring towns. Consequently, the estimated coefficient for $W^{*} y$ represents the impact of the variation of $y$ in the neighbors over the town under study. To facilitate the results analysis and discussion, the spatial weights matrix used in this study was normalized in the column. Thus, $W^{*} y$ cannot be understood as the mean of the variable in neighboring towns, but the estimated coefficient for this variable represents the impact of the variation of $y$ in the town under study over the neighbors.) (resp., $y$ and $W^{*} y$ ), average real income of all jobs $(w)$, average real income of jobs in agriculture $\left(w^{A}\right)$, proportion of working adults $(u)$, proportion of adults working in agriculture $\left(u^{A}\right)$, municipal and spatially lagged proportion of adults in the population (resp., $r$ and $W^{*} r$ ), and municipal and spatially lagged share of farming land in the total area of the town (resp., $s^{f}$ and $W^{*} s^{f}$ ), municipal and spatially lagged share of the area given to agriculture in total farmland (resp., $s_{f}^{a}$ and $W^{*} s_{f}^{a}$ ), municipal and spatially lagged share of land for sugarcane in agricultural land (resp., $s_{a}^{c}$ and $W^{*} s_{a}^{c}$ ). These series constitute a balanced panel containing the 645 towns in São Paulo State (according to IBGE's [1] municipal shapefile database of 2005) ranging from 2000 to 2008 , with a total of 5805 observations.

As this is a panel data analysis, the variables can be broken down into between and within dimensions. The between dimension is the variation of the mean in time between towns $\left(\bar{x}_{j}\right)$, whereas the within dimension characterizes deviation in relation to each municipal mean $\left(x_{j t}-\bar{x}_{j}+\overline{\bar{x}}_{j}\right.$, where $\overline{\bar{x}}_{j}$ is the total mean). The real per capita GDP, for instance, varied from \$ 1864.77 to $\$ 125706.23$ during the period 
TABLE 1: Descriptive statistics of continuous variables.

\begin{tabular}{|c|c|c|c|c|c|c|c|}
\hline Variable & Unit & Dimension & Mean & SD & Minimum & Maximum & Observations \\
\hline \multirow{3}{*}{$y$} & \multirow{3}{*}{$\$$ of 2008} & Total & 8111.36 & 7255.07 & 1864.77 & 125706.23 & $N=5805$ \\
\hline & & Between & & 6799.25 & 2229.97 & 74337.27 & $n=645$ \\
\hline & & Within & & 2543.61 & -31077.14 & 70424.86 & $T=9$ \\
\hline \multirow{3}{*}{$W^{*} y$} & \multirow{3}{*}{$\$$ of 2008} & Total & 8111.36 & 3056.62 & 2731.34 & 30396.11 & $N=5805$ \\
\hline & & Between & & 2927.69 & 3148.45 & 23390.70 & $n=645$ \\
\hline & & Within & & 885.07 & 3286.03 & 16215.60 & $T=9$ \\
\hline \multirow{3}{*}{$w$} & \multirow{3}{*}{$\$$ of 2008} & Total & 563.56 & 184.61 & 156.82 & 3289.10 & $N=5805$ \\
\hline & & Between & & 167.32 & 339.55 & 1425.37 & $n=645$ \\
\hline & & Within & & 78.25 & -172.40 & 3044.02 & $T=9$ \\
\hline \multirow{3}{*}{$w^{A}$} & \multirow{3}{*}{$\$$ of 2008} & Total & 371.98 & 143.40 & 0.00 & 4349.73 & $N=5805$ \\
\hline & & Between & & 112.92 & 0.00 & 1042.14 & $n=645$ \\
\hline & & Within & & 88.49 & -244.26 & 3739.49 & $T=9$ \\
\hline \multirow{3}{*}{$u$} & \multirow{3}{*}{$\%$} & Total & 23.60 & 17.66 & 2.94 & 298.91 & $N=5805$ \\
\hline & & Between & & 16.04 & 5.65 & 247.05 & $n=645$ \\
\hline & & Within & & 7.40 & -102.50 & 132.48 & $T=9$ \\
\hline \multirow{3}{*}{$u^{A}$} & \multirow{3}{*}{$\%$} & Total & 4.48 & 6.97 & 0.00 & 197.02 & $N=5805$ \\
\hline & & Between & & 5.61 & 0.00 & 53.74 & $n=645$ \\
\hline & & Within & & 4.14 & -38.44 & 174.51 & $T=9$ \\
\hline \multirow{3}{*}{$r$} & \multirow{3}{*}{$\%$} & Total & 75.50 & 3.53 & 61.55 & 92.51 & $N=5805$ \\
\hline & & Between & & 3.15 & 63.64 & 85.49 & $n=645$ \\
\hline & & Within & & 1.61 & 63.26 & 82.52 & $T=9$ \\
\hline \multirow{3}{*}{$W^{*} r$} & \multirow{3}{*}{$\%$} & Total & 75.50 & 8.57 & 26.62 & 110.14 & $N=5805$ \\
\hline & & Between & & 8.44 & 27.31 & 106.82 & $n=645$ \\
\hline & & Within & & 1.54 & 71.38 & 78.82 & $T=9$ \\
\hline \multirow{3}{*}{$s^{f}$} & \multirow{3}{*}{$\%$} & Total & 69.90 & 32.00 & 0.00 & 330.88 & $N=5805$ \\
\hline & & Between & & 29.95 & 0.00 & 311.34 & $n=645$ \\
\hline & & Within & & 11.34 & -32.67 & 297.82 & $T=9$ \\
\hline \multirow{3}{*}{$W^{*} s^{f}$} & \multirow{3}{*}{$\%$} & Total & 69.90 & 24.79 & 0.69 & 133.19 & $N=5805$ \\
\hline & & Between & & 24.54 & 1.84 & 128.63 & $n=645$ \\
\hline & & Within & & 3.61 & 50.12 & 85.96 & $T=9$ \\
\hline \multirow{3}{*}{$s_{f}^{a}$} & \multirow{3}{*}{$\%$} & Total & 36.24 & 30.93 & 0.00 & 100.00 & $N=5805$ \\
\hline & & Between & & 29.37 & 0.00 & 99.16 & $n=645$ \\
\hline & & Within & & 9.74 & -52.65 & 125.13 & $T=9$ \\
\hline \multirow{3}{*}{$W^{*} s_{f}^{a}$} & \multirow{3}{*}{$\%$} & Total & 36.24 & 22.92 & 0.00 & 103.63 & $N=5805$ \\
\hline & & Between & & 22.48 & 0.35 & 99.36 & $n=645$ \\
\hline & & Within & & 4.57 & 18.33 & 78.59 & $T=9$ \\
\hline & & Total & 31.00 & 33.13 & 0.00 & 99.21 & $N=5805$ \\
\hline$s_{a}^{c}$ & $\%$ & Between & & 30.72 & 0.00 & 98.43 & $n=645$ \\
\hline & & Within & & 12.47 & -52.41 & 116.41 & $T=9$ \\
\hline & & Total & 31.00 & 23.80 & 0.00 & 92.11 & $N=5805$ \\
\hline$W^{*} s_{a}^{c}$ & $\%$ & Between & & 22.48 & 0.00 & 82.95 & $n=645$ \\
\hline & & Within & & 7.88 & 2.14 & 76.26 & $T=9$ \\
\hline
\end{tabular}

Source: research results.

under study. The mean in time of real per capita GDP in the towns (between) varied from \$ 2229.97 to \$ 74337.27, and the deviations in relation to these municipal means (within) varied from $\$-31077.14$ to $\$ 70424.86$. But this does not mean that these really were the extreme variations of real per capita PIB in relation to its own mean. Indeed, as the total mean was added to the within number, the lowest and highest deviations observed were \$ -39188.50 and \$ 62 313.51, respectively.

It is interesting to note that some towns had total labour utilization rate $(u)$ and the rate in agriculture $\left(u^{A}\right)$ of over $100 \%$. This means that some towns have more jobs than the total adult population. A possible explanation for this phenomenon is that some workers in these towns have more 
TABLE 2: Descriptive statistics related to the discrete variable.

\begin{tabular}{cccccc}
\hline & \multicolumn{2}{c}{ Total } & \multicolumn{2}{c}{ Between } & Within \\
& Frequency & $\%$ & Frequency & $\%$ & $\%$ \\
\hline$D^{U}$ & & & & & \\
0 & 4729 & 81.46 & 536 & 83.10 & 98.03 \\
1 & 1076 & 18.54 & 143 & 22.17 & 83.61 \\
Total & $\mathbf{5 0 8 5}$ & $\mathbf{1 0 0 . 0 0}$ & $\mathbf{6 7 9}$ & $\mathbf{1 0 5 . 2 7}$ & $\mathbf{9 4 . 9 9}$ \\
$W^{*} D^{U}$ & & & & & \\
0 & 1267 & 21.83 & 144 & 22.33 & 97.76 \\
$>0$ & 4538 & 78.17 & 515 & 79.84 & 97.91 \\
Total & $\mathbf{5 8 0 5}$ & $\mathbf{1 0 0 . 0 0}$ & $\mathbf{6 5 9}$ & $\mathbf{1 0 2 . 1 7}$ & $\mathbf{9 7 . 8 8}$ \\
\hline
\end{tabular}

Source: research results.

than one job. Another plausible explanation is that many workers reside in one town and work in a neighbouring town. In this case, the labour utilization rate is reduced in the town where the worker resides but increases in the town where he works.

Another peculiar point concerning the series under study is that the share of farmland (crops, pasture, and forestry) is also higher than $100 \%$ of the territory of some towns. But this can be accounted for by the fact that some agricultural and forestry systems combine forestry with crops and/or pasture in the same area. Besides that, some temporary crops can be combined so that the same area produces two or even three harvests in the same year.

Table 2 shows some descriptive statistics related to the only discrete variable in the model, the dummy $D^{U}$, which has the value of 1 when the town has an operational plant and/or distillery in the year in question and the value of 0 otherwise. The total frequency indicates that $18.54 \%$ of towns in the state had at least one operational industrial unit in the sugarcane sector during the time under study. The between frequency indicates that 143 towns had a $D^{U}=1$ value in some of the years of the sample, while 536 had a value of $D^{U}=0$. As the sample is made up of 645 towns, this means that $D^{U}$ was altered in 34 towns between 2000 and 2008. The within dimensions shows that, on average, the towns that had a value of $D^{U}=1$ at some time remained at this level in $83.61 \%$ during the time in question.

To capture the indirect effect, that is, the impact on the fifteen closest towns, of making a plant and/or distillery operational, the spatial lag of the binary variable $\left(W^{*} D^{U}\right)$ was also included in the model. Although $W^{*} D^{U}$ is not a binary variable, some of its descriptive statistics are also shown in Table 2, merely to facilitate comparison with the original $D^{U}$ variable. For instance, whereas 143 towns at some time had sugarcane sector units in operation, 515 felt their influence (in accordance with the criteria adopted to define $W^{*}$ ).

The data in Table 3 show that $99.2 \%$ of the towns with $D^{U}=0$ at some time did not have an industrial unit for the sugarcane sector in operation the following year. Analogously, $98.8 \%$ of the towns with $W^{*} D^{U}=0$ at some time remained uninfluenced indirectly by a plant and/or distillery in operation the following year. Furthermore, it is important to point out that there were no cases of towns
TABLE 3: Distribution of observations by transition of the dummy variable over time.

\begin{tabular}{|c|c|c|c|c|c|c|}
\hline & \multicolumn{3}{|c|}{ Frequency } & \multicolumn{3}{|c|}{$\%$} \\
\hline & 0 & 1 & Total & 0 & 1 & Total \\
\hline \multicolumn{7}{|l|}{$D^{U}$} \\
\hline 0 & 4193 & 34 & 4227 & 99.20 & 0.80 & 100.00 \\
\hline 1 & 0 & 933 & 933 & 0.00 & 100.00 & 100.00 \\
\hline \multirow[t]{3}{*}{ Total } & 4193 & 967 & 5160 & 81.26 & 18.74 & 100.00 \\
\hline & \multicolumn{3}{|c|}{ Frequency } & \multicolumn{3}{|c|}{$\%$} \\
\hline & 0 & $>0$ & Total & 0 & $>0$ & Total \\
\hline \multicolumn{7}{|l|}{$W^{*} D^{U}$} \\
\hline 0 & 1123 & 14 & 1137 & 98.77 & 1.23 & 100.00 \\
\hline$>0$ & 0 & 4023 & 4023 & 0.00 & 100.00 & 100.00 \\
\hline Total & 1123 & 4037 & 5160 & 21.76 & 78.24 & 100.00 \\
\hline
\end{tabular}

Source: research results.

which at some time had an operational unit and later did not or were under its influence and then ceased to be. From 2000 to 2008, 34 towns were added to the group of 109 towns which were directly influenced by the sector, and fourteen were added to the group of 501 that were already indirectly influenced early on.

The estimated parameters of the system-GMM obtained by the robust two-step estimator (In the two-step estimate, the covariance matrix is robust to the correlation and the specific heteroscedasticity of the panel, but the standard errors are biased (downwards). The robust two-step procedure corrects the covariance matrix for the case of the finite sample. However, it is worth pointing out that, in the latter case, it is not possible to conduct the Sargan test to verify the adequacy of the instruments used for estimation in the model.) are shown in Table 4. The coefficients associated with the variables that filter time $\left(y_{t-1}\right)$ and space $\left(W^{*} y\right)$, both different from zero at a significance level of $1 \%$, corroborate the existence of a moderate temporal dependence (0.568) and a small spatial dependence (0.306), both positive, in per capita GDP. The Wald $\chi^{2}$ test shows that the set of explanatory variables is adequate to predict the behaviour of the dependent variable. The second-order autocorrelation test (statistic $m_{2}$, Arellano-Bond [22]) shows no serial autocorrelation in the level residuals, and the first-order correlation test (statistic $m_{1}$, Arellano-Bond [22]) confirms that the system-GMM is the most adequate model.

Nevertheless, it is worth highlighting that the coefficients associated with the explanatory variables and their respective spatial lags cannot be directly interpreted. Unlike static models, they do not represent partial derivatives that measure the response of the dependent variable to alterations of the explanatory variables. In a spatial dynamic panel model, the partial derivatives are nonlinear functions of the estimated coefficients and the autoregressive terms in time and space that assume the form of $N \times N$ matrix for each time horizon. As the coefficients associated with the indirect effects of some variables were not significant (namely, $W^{*} D^{U}, W^{*} s_{f}^{a}$, and $W^{*} s^{f}$ ), these were not taken into consideration in this study. As the significance level of these coefficients was moderate, 
TABLE 4: System-GMM model estimation results.

\begin{tabular}{|c|c|c|c|c|}
\hline & Coefficient & SE & $z$ & $P>|z|$ \\
\hline$y_{t-1}$ & 0.568 & 0.022 & 26.35 & 0.000 \\
\hline$W^{*} y$ & 0.306 & 0.071 & 4.31 & 0.000 \\
\hline$D^{U}$ & 3456.043 & 1060.243 & 3.26 & 0.001 \\
\hline$W^{*} D^{U}$ & -2400.948 & 2667.930 & -0.90 & 0.368 \\
\hline$s_{a}^{c}$ & 12.583 & 5.617 & 2.24 & 0.025 \\
\hline$W^{*} s_{a}^{c}$ & -60.132 & 15.207 & -3.95 & 0.000 \\
\hline$s_{f}^{a}$ & 20.669 & 8.505 & 2.43 & 0.015 \\
\hline$W^{*} s_{f}^{a}$ & -23.194 & 20.274 & -1.14 & 0.253 \\
\hline$s^{f}$ & 13.729 & 5.108 & 2.69 & 0.007 \\
\hline$W^{*} s^{f}$ & 6.474 & 12.453 & 0.52 & 0.603 \\
\hline$r$ & 22.762 & 138.061 & 0.16 & 0.869 \\
\hline$W^{*} r$ & 104.596 & 146.678 & 0.71 & 0.476 \\
\hline$w$ & 5.091 & 1.491 & 3.42 & 0.001 \\
\hline$w^{A}$ & 2.837 & 1.243 & 2.28 & 0.023 \\
\hline$u$ & 24.852 & 21.496 & 1.16 & 0.248 \\
\hline$u^{A}$ & -127.360 & 53.828 & -2.37 & 0.018 \\
\hline Constant & -14964.800 & 4933.162 & -3.03 & 0.002 \\
\hline Instruments for equation in differences & \multicolumn{4}{|c|}{$y_{t-2}, W^{*} y_{t-2}, w_{t-2}, w_{t-2}^{A}, u_{t-2}, u_{t-2}^{A}$} \\
\hline Instruments for equation in level & \multicolumn{4}{|c|}{$\Delta y_{t-1}, \Delta W^{*} y_{t-1}, \Delta w_{t-1}, \Delta w_{t-1}^{A}, \Delta u_{t-1}, \Delta u_{t-1}^{A}$} \\
\hline Wald $(P)$ & \multicolumn{4}{|c|}{0.000} \\
\hline 1st-order autocorrelation $(P)$ & \multicolumn{4}{|c|}{0.042} \\
\hline 2nd-order autocorrelation $(P)$ & \multicolumn{4}{|c|}{0.517} \\
\hline Observations & \multicolumn{4}{|c|}{5805} \\
\hline
\end{tabular}

Source: research results.

Satolo [23] discussed the same results, taking all the estimated coefficients into account.

The direct and indirect effects on real per capita municipal GDP of a permanent increase of ten percentage points (p.p.) in the share of farmland $\left(s^{f}\right)$ are shown in Table 5 . The direct contemporaneous effect indicates that, on average, an increase of ten percentage points in farmland raises the real per capita PIB by $\$ 75.54$ in a town where this expansion occurred. Furthermore, the indirect contemporaneous effect shows that there is a small positive spillover, equivalent to an increase of \$ 2.17 in the real per capita GDP of each of the 15 closest town. (Using the simplifying assumption that the indirect effects would be restricted only to the fifteen nearest towns, these were divided by 15 to make the results comparable to the direct effects at the municipal level. As the estimated spatial dependence coefficient for the independent variable is small, the impacts dissipate rapidly in space, with most of the indirect effect concentrated in the 15 nearest towns. But it is worth emphasizing that the indirect effects were calculated as the mean of the sum of the impacts of the change of an independent variable on a certain town over the dependent variables of all the 644 other towns in São Paulo State.) As the model is dynamic, this shock in the farming area spreads spatially over time, and, after ten years, the direct cumulative effect is equivalent to an increase of $\$ 182.33$ in real per capita GDP of a town where the expansion of farming occurred, associated with an increase equivalent to \$ 23.19 of the real per capita GDP of each of the 15 nearest towns.
TABLE 5: Impact on real per capita GDP (in \$ of 2008) of a 10 p.p. permanent increase in the share of farmland relative to the entire municipal area.

\begin{tabular}{ccccc}
\hline & \multicolumn{2}{c}{$\begin{array}{c}\text { Average municipal } \\
\text { effect }\end{array}$} & \multicolumn{2}{c}{$\begin{array}{c}\text { Accumulated average } \\
\text { municipal effect }\end{array}$} \\
& Direct & Indirect & Direct & Indirect \\
\hline $\begin{array}{l}\text { Contemporaneous } \\
\text { Years forward }\end{array}$ & 75.54 & 2.17 & 75.54 & 2.17 \\
1 & & & & \\
2 & 43.55 & 3.00 & 119.08 & 5.17 \\
3 & 25.37 & 3.14 & 144.45 & 8.31 \\
4 & 14.96 & 2.96 & 159.41 & 11.27 \\
5 & 8.96 & 2.64 & 168.36 & 13.91 \\
6 & 5.45 & 2.28 & 173.81 & 16.20 \\
7 & 3.39 & 1.95 & 177.21 & 18.14 \\
8 & 2.15 & 1.63 & 179.36 & 19.77 \\
9 & 1.40 & 1.36 & 180.76 & 21.13 \\
10 & 0.93 & 1.13 & 181.69 & 22.26 \\
& 0.64 & 0.93 & 182.33 & 23.19 \\
\hline
\end{tabular}

Source: research results.

Indirect effects were divided by 15 in order to turn the results comparable at the municipal level.

Table 6 shows the direct and indirect effects on the real per capita GDP of a permanent increase of ten percentage points on the share of agriculture in farming $\left(s_{f}^{a}\right)$. 
TABLE 6: Impact on real per capita GDP (in \$ of 2008) of a 10 p.p. permanent increase in the share of agriculture relative to the municipal farmland area.

\begin{tabular}{ccccc}
\hline & \multicolumn{2}{c}{$\begin{array}{c}\text { Average municipal } \\
\text { effect }\end{array}$} & \multicolumn{2}{c}{$\begin{array}{c}\text { Accumulated average } \\
\text { municipal effect }\end{array}$} \\
& Direct & Indirect & Direct & Indirect \\
\hline $\begin{array}{l}\text { Contemporaneous } \\
\text { Years forward }\end{array}$ & 113.72 & 3.27 & 113.72 & 3.27 \\
1 & 65.56 & 4.51 & 179.28 & 7.79 \\
2 & 38.19 & 4.73 & 217.47 & 12.51 \\
3 & 22.52 & 4.45 & 239.99 & 16.97 \\
4 & 13.48 & 3.97 & 253.47 & 20.94 \\
5 & 8.21 & 3.44 & 261.68 & 24.38 \\
6 & 5.10 & 2.92 & 266.78 & 27.31 \\
7 & 3.24 & 2.46 & 270.03 & 29.77 \\
8 & 2.11 & 2.05 & 272.14 & 31.81 \\
9 & 1.41 & 1.70 & 273.54 & 33.51 \\
10 & 0.96 & 1.40 & 274.50 & 34.91 \\
\hline
\end{tabular}

Source: research results.

Indirect effects were divided by 15 in order to turn the results comparable at the municipal level.

Contemporaneously, this relative growth in agriculture has a direct positive effect of $\$ 113.72$ on the real per capita GDP of the town where this expansion takes place and a small positive indirect effect of, on average, \$3.27 on the real per capita GDP of the 15 nearest towns. After ten years, the cumulative effect is equivalent to an increase of $\$ 274.50$ in a town where the expansion occurred and an increase of \$ 34.91 in each of the 15 closest neighbouring towns.

Meanwhile, the direct and indirect effects of a permanent increase of ten percentage points of area given over to sugarcane within the area given over to agriculture $\left(s_{a}^{c}\right)$ can be seen in Table 7. Contemporaneously, real per capita GDP increases by $\$ 61.91$ in the town where this expansion occurs and drops by an average of $\$ 29.10$ in the 15 nearest towns. After ten years, the total cumulative effect is equivalent to an increase of \$ 108.01 in real per capita GDP in the town where this expansion took place and a reduction of $\$ 129.62$ in each of the 15 closest neighbouring towns.

Therefore, based on the results shown in Tables 5 and 6, it can be said that the expansion of farming and the increasing importance of agriculture for farming in towns in São Paulo State have positive impacts on real per capita GDP. But the increasing importance of sugarcane for agriculture in a town has a negative impact on real per capita GDP (Table 7) when one considers the total effect on São Paulo State (Impact $=$ Total effect in São Paulo State $=$ Direct Effect $+15 *$ (Average Indirect Effect)).

This does not mean that the expansion of sugarcane in the state's towns has a negative impact on real per capita GDP. As the direct and indirect effects were calculated from a comparative static analysis, the findings and the variables $s_{a}^{c}$, $s_{f}^{a}$ and $s^{f}$ need to be combined to evaluate better the impact of the expansion (in area) of sugarcane in the state's towns on real per capita GDP.
TABLE 7: Impact on real per capita GDP (in \$ of 2008) of a 10 p.p. permanent increase in the share of sugarcane relative to the municipal area given over to agriculture.

\begin{tabular}{ccccc}
\hline & \multicolumn{2}{c}{$\begin{array}{c}\text { Average municipal } \\
\text { effect }\end{array}$} & \multicolumn{2}{c}{$\begin{array}{c}\text { Accumulated average } \\
\text { municipal effect }\end{array}$} \\
& Direct & Indirect & Direct & Indirect \\
\hline $\begin{array}{l}\text { Contemporaneous } \\
\text { Years forward }\end{array}$ & 61.91 & -29.10 & 61.91 & -29.10 \\
1 & & & & \\
2 & 30.55 & -22.48 & 92.45 & -51.57 \\
3 & 14.16 & -17.68 & 106.61 & -69.25 \\
4 & 5.78 & -14.08 & 112.39 & -83.33 \\
5 & 1.64 & -11.32 & 114.03 & -94.65 \\
6 & -0.28 & -9.16 & 113.74 & -103.81 \\
7 & -1.07 & -7.44 & 112.67 & -111.25 \\
8 & -1.30 & -6.07 & 111.37 & -117.32 \\
9 & -1.27 & -4.95 & 110.09 & -122.26 \\
10 & -1.13 & -4.04 & 108.97 & -126.31 \\
\hline
\end{tabular}

Source: research results.

Indirect effects were divided by 15 in order to turn the results comparable at the municipal level.

On the one extreme is the case in which sugarcane expansion occurs only in places that had already been used for agriculture to substitute other crops $\left(\Delta s_{a}^{c} \mid s_{f}^{a}, s^{f}=\right.$ constant). In this case, the direct and indirect effects shown in Table 7 also represent the impact of sugarcane expansion on the town. On the other hand, if sugarcane expansion is accompanied by an expansion of other crops and its share of the state's agriculture remains unchanged $\left(\Delta s_{f}^{a} \mid s_{a}^{c}, s^{f}=\right.$ constant), the direct and indirect effects shown in Table 6 also represent the impact of sugarcane expansion on the town. The difference is that, in the first case, the sugarcane expansion is assumed to have taken place exclusively substituting other crops, whereas in the second case, it is assumed to have taken place exclusively replacing pasture land and planted forests.

On the other extreme, there is a third case, in which sugarcane expansion takes place in areas that had not previously been used as farmland and there is no activity replacement $\left(\Delta s^{f} \mid s_{a}^{c}, s_{f}^{a}=\right.$ constant $)$, as shown in the results of Table 5. In any other intermediate scenario imaginable for sugarcane expansion (in area) in the districts and towns of São Paulo State, the result will be a combination of the results shown for these extreme cases and depends on the relative variation of $s_{a}^{c}, s_{f}^{a}$, and $s^{f}$. Thus, it can be said that the impact of sugarcane expansion (in area) on the real per capita GDP of a town can be either positive or negative, depending on to what extent this expansion takes place as a replacement of other farming activities.

The direct and indirect effects of making an industrial plant and/or distillery operational on real per capita GDP are shown in Table 8. In the year when the industrial unit becomes operational, the real per capita GDP increases by $\$$ 1901.44 in the town where the unit is located and by $\$ 54.73$ in the 15 nearest towns. After ten years of operations of the plant 
TABLE 8: Impact on real per capita GDP (in \$ of 2008) of the beginning of operations in an average industrial plant of sugarcane sector.

\begin{tabular}{ccccc}
\hline & \multicolumn{2}{c}{$\begin{array}{c}\text { Average municipal } \\
\text { effect }\end{array}$} & \multicolumn{2}{c}{$\begin{array}{c}\text { Accumulated average } \\
\text { municipal effect }\end{array}$} \\
& Direct & Indirect & Direct & Indirect \\
\hline $\begin{array}{c}\text { Contemporaneous } \\
\text { Years forward }\end{array}$ & 1901.44 & 54.73 & 1901.44 & 54.73 \\
1 & 1096.24 & 75.48 & 2997.68 & 130.21 \\
2 & 638.51 & 79.04 & 3636.20 & 209.26 \\
3 & 376.55 & 74.45 & 4012.74 & 283.70 \\
4 & 225.39 & 66.46 & 4238.14 & 350.17 \\
5 & 137.29 & 57.55 & 4375.43 & 407.72 \\
6 & 85.32 & 48.92 & 4460.75 & 456.63 \\
7 & 54.22 & 41.08 & 4514.97 & 497.72 \\
8 & 35.28 & 34.23 & 4550.25 & 531.96 \\
9 & 23.54 & 28.38 & 4573.78 & 560.34 \\
10 & 16.08 & 23.44 & 4589.86 & 583.78 \\
\hline
\end{tabular}

Source: research results.

Indirect effects were divided by 15 in order to turn the results comparable at the municipal level.

and/or distillery, the total cumulative effect is equivalent to a rise of $\$ 4589.86$ in real per capita GDP in the town where the unit is located and on average $\$ 583.78$ in the 15 closest towns. Using the average real per capita GDP in the towns of São Paulo State in 2008 as a reference point (\$ 8469.09), making a plant and/or distillery operational represents an increase ranging from $22.45 \%$ (in the short term) to $54.20 \%$ (after 10 years) in the income per capita of the town where the unit is located and an average increase of $0.65 \%$ (in the short term) and $6.89 \%$ (after 10 years) in the 15 nearest towns.

Knowing the direct and indirect effects of sugarcane expansion and of making an industrial plant and/or distillery operational, it is possible to calculate the impact of the expansion of the sugarcane sector on the real per capita GDP of towns in São Paulo State. The results of the spatial dynamic panel model enable an evaluation of this impact when an industrial unit becomes operational in three different scenarios for the expansion of sugarcane: when it substitutes other crops (Tables 9 and 10), when it replaces pasture land and planted forests (Tables 11 and 12), and when it takes place in areas that had not previously been used for farming (Tables 13 and 14). These effects were obtained by a linear combination of the total effects presented by variables $s^{f}, s_{f}^{a}$, $s_{a}^{c}$, and $D^{U}$.

It is important to emphasize that, as shown in Tables 9,11 , and 13, the direct effect of the expanding sugarcane sector (industrial plant + sugarcane) on real per capita GDP in the towns was positive in every scenario considered for sugarcane expansion. Regarding the indirect effect, some relatively small impacts on the real per capita GDP of the 15 closest towns can be seen if the expansion of the sugarcane sector occurs by replacing other crops in an area larger than $40 \%$ of the territory in towns with an operational industrial plant. Otherwise, the indirect effects of the expansion of the sector are also positive.

Concerning the total effects (Tables 10, 12, and 14), the expansion of the sugarcane sector has a positive impact on the real per capita GDP of towns when the expansion of the land used for sugarcane, in conjunction with the initial operations of a new plant and/or distillery, does not take place as a replacement for other crops. If the sugarcane plantation expands in detriment of other crops, the impact can be either positive or negative, depending on how intensely this replacement is implemented. For instance, assuming that $\Delta s^{f}=0$ and $\Delta s_{f}^{a}=0$, the expansion of the sugarcane sector has a positive impact on real per capita GDP if the expansion of the sugarcane plantation is lower than 72.68 percentage points of municipal territory. Above this level, the indirect negative effects that probably originate from less diversification in local agriculture overlap the direct positive effects of the expanding sector and the impact turns negative. (It is very common for expansion not to be limited to the town where the industrial unit of the sugarcane sector is located and there is a spillover to the nearest towns. As the analysis is indifferent about where this expansion occurs, the impacts of the sugarcane sector are equivalent if the expansion of the planted area of sugarcane is $X$ percentage points of the territory of only one town or $X / n$ percentage points of the territory of the $n$ nearest towns.)

Considering the real per capita GDP as a proxy of the real per capita income, the total estimated effects of the proposed model lead to the conclusion that the sugarcane sector has a positive impact on the average per capita income level in São Paulo State when the expansion of sugarcane occurs in areas that had not been previously occupied by farming or to substitute areas of pasture and planted forests. If the expansion leads to a substitution of other crops in an area equal to a share that is equivalent to up to $72.68 \%$ of the territory of a town with a plant or distillery, the impact of the expansion of the sugarcane sector on the average per capita income is also positive.

\section{Conclusion}

Considering the impact of the expansion of the sugarcane sector as the sum of the total effect of the beginning of plants and/or distilleries operations and the total effect of the sugarcane expansion, one can say that sugarcane sector expansion had a positive impact on the real municipal per capita GDP when the expansion of sugarcane plantations did not occur exclusively to substitute other crops in São Paulo State. With the installation of a new industrial unit in the sector, if the expansion of sugarcane substitutes other crops (without there being an expansion of the total farmland and without variations in the total farmland), the impact is still positive if this expansion takes place in an area that occupies up to $72.68 \%$ of municipal territory. 
TABLE 9: Direct and indirect effects of sugarcane sector expansion on real per capita GDP (in \$ of 2008 and as \% of the average municipal per capita GDP in 2008), assuming that sugarcane expansion occurred exclusively in substitution to other crops.

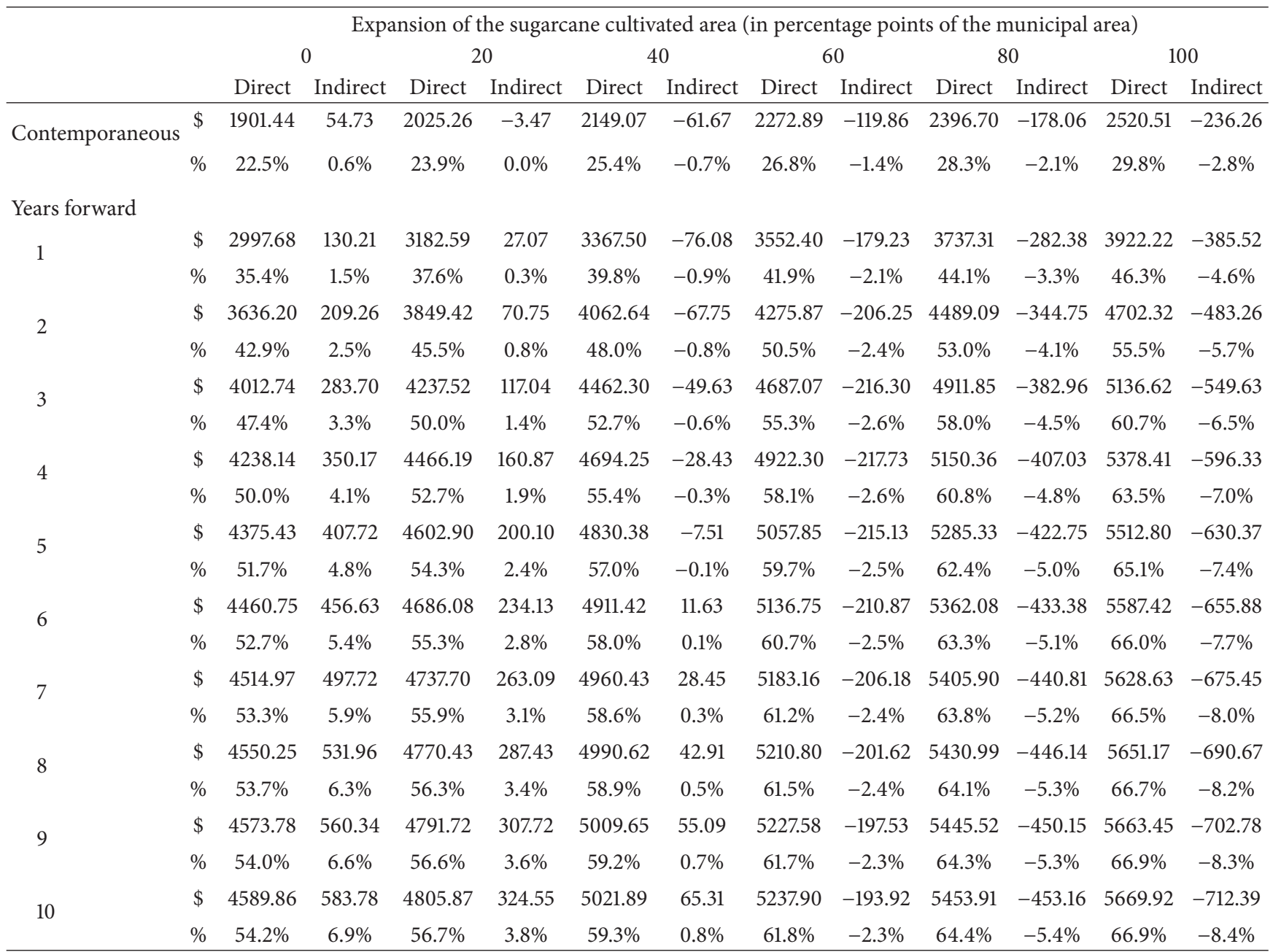

Source: research results.

Effects calculated with the combination of the results shown in Tables 7 and 8.

TABLE 10: Total effect of sugarcane sector expansion on real per capita GDP (in \$ of 2008), assuming that sugarcane expansion occurs exclusively in substitution to other crops.

\begin{tabular}{lccccccccccccc}
\hline & \multicolumn{10}{c}{ Expansion of the sugarcane cultivated area (in percentage points of the municipal area) } \\
& 0 & 10 & 20 & 30 & 40 & 50 & 60 & 70 & 80 & 90 & 100 \\
\hline $\begin{array}{l}\text { Contemporaneous } \\
\text { Years forward }\end{array}$ & 2722.37 & 2347.80 & 1973.23 & 1598.67 & 1224.10 & 849.53 & 474.96 & 100.39 & -274.17 & -648.74 & -1023.31 \\
1 & & & & & & & & & & & \\
2 & 4950.85 & 4269.70 & 3588.55 & 2907.39 & 2226.24 & 1545.09 & 863.93 & 182.78 & -498.37 & -1179.52 & -1860.68 \\
3 & 6775.04 & 5842.89 & 4910.73 & 3978.57 & 3046.41 & 2114.25 & 1182.09 & 249.93 & -682.22 & -1614.38 & -2546.54 \\
4 & 8268.30 & 7130.68 & 5993.07 & 4855.46 & 3717.85 & 2580.23 & 1442.62 & 305.01 & -832.60 & -1970.21 & -3107.83 \\
5 & 9490.64 & 8184.91 & 6879.19 & 5573.46 & 4267.73 & 2962.01 & 1656.28 & 350.55 & -955.17 & -2260.90 & -3566.63 \\
6 & 10491.23 & 9047.84 & 7604.44 & 6161.05 & 4717.66 & 3274.26 & 1830.87 & 387.48 & -1055.92 & -2499.31 & -3942.70 \\
7 & 11310.29 & 9754.19 & 8198.08 & 6641.98 & 5085.87 & 3529.77 & 1973.67 & 417.56 & -1138.54 & -2694.64 & -4250.75 \\
8 & 11980.76 & 10332.37 & 8683.98 & 7035.60 & 5387.21 & 3738.82 & 2090.43 & 442.04 & -1206.34 & -2854.73 & -4503.12 \\
9 & 12529.59 & 10805.75 & 9081.91 & 7358.07 & 5634.22 & 3910.38 & 2186.54 & 462.70 & -1261.14 & -2984.98 & -4708.83 \\
10 & 12978.86 & 11193.15 & 9407.45 & 7621.74 & 5836.04 & 4050.33 & 2264.63 & 478.92 & -1306.78 & -3092.49 & -4878.19 \\
\hline & 13346.62 & 11510.36 & 9674.10 & 7837.85 & 6001.59 & 4165.33 & 2329.08 & 492.82 & -1343.44 & -3179.69 & -5015.95 \\
\hline
\end{tabular}

Source: research results.

Effects calculated with the combination of the results shown in Table 9. 
TABLE 11: Direct and indirect effects of sugarcane sector expansion on real per capita GDP (in \$ of 2008 and as \% of the average municipal per capita GDP in 2008), assuming that the share of sugarcane in the agriculture remains constant (substitution of pasture and planted forests).

\begin{tabular}{|c|c|c|c|c|c|c|c|c|c|c|c|c|c|}
\hline & & \multicolumn{12}{|c|}{ Expansion of the sugarcane cultivated area (in percentage points of the municipal area) } \\
\hline & & \multicolumn{2}{|c|}{0} & \multicolumn{2}{|c|}{20} & \multicolumn{2}{|c|}{40} & \multicolumn{2}{|c|}{60} & \multicolumn{2}{|c|}{80} & \multicolumn{2}{|c|}{100} \\
\hline & & Direct & Indirect & Direct & Indirect & Direct & Indirect & Direct & Indirect & Direct & Indirect & Direct & Indirect \\
\hline \multirow{2}{*}{ Contemporaneous } & $\$$ & 1901.44 & 54.73 & 2128.88 & 61.27 & 2356.32 & 67.82 & 2583.75 & 74.37 & 2811.19 & 80.91 & 3038.63 & 87.46 \\
\hline & $\%$ & $22.5 \%$ & $0.6 \%$ & $25.1 \%$ & $0.7 \%$ & $27.8 \%$ & $0.8 \%$ & $30.5 \%$ & $0.9 \%$ & $33.2 \%$ & $1.0 \%$ & $35.9 \%$ & $1.0 \%$ \\
\hline \multicolumn{14}{|l|}{ Years forward } \\
\hline \multirow[t]{2}{*}{1} & $\$$ & 2997.68 & 130.21 & 3356.25 & 145.79 & 3714.81 & 161.36 & 4073.37 & 176.93 & 4431.93 & 192.51 & 4790.50 & 208.09 \\
\hline & $\%$ & $35.4 \%$ & $1.5 \%$ & $39.6 \%$ & $1.7 \%$ & $43.9 \%$ & $1.9 \%$ & $48.1 \%$ & $2.1 \%$ & $52.3 \%$ & $2.3 \%$ & $56.6 \%$ & $2.5 \%$ \\
\hline \multirow{2}{*}{2} & $\$$ & 3636.20 & 209.26 & 4071.13 & 234.28 & 4506.07 & 259.32 & 4941.01 & 284.34 & 5375.95 & 309.38 & 5810.88 & 334.40 \\
\hline & $\%$ & $42.9 \%$ & $2.5 \%$ & $48.1 \%$ & $2.8 \%$ & $53.2 \%$ & $3.1 \%$ & $58.3 \%$ & $3.4 \%$ & $63.5 \%$ & $3.7 \%$ & $68.6 \%$ & $3.9 \%$ \\
\hline \multirow[t]{2}{*}{3} & $\$$ & 4012.74 & 283.70 & 4492.72 & 317.64 & 4972.70 & 351.57 & 5452.68 & 385.51 & 5932.66 & 419.44 & 6412.63 & 453.38 \\
\hline & $\%$ & $47.4 \%$ & $3.3 \%$ & $53.0 \%$ & $3.8 \%$ & $58.7 \%$ & $4.2 \%$ & $64.4 \%$ & $4.6 \%$ & $70.1 \%$ & $5.0 \%$ & $75.7 \%$ & $5.4 \%$ \\
\hline \multirow[t]{2}{*}{4} & $\$$ & 4238.14 & 350.17 & 4745.07 & 392.05 & 5252.01 & 433.93 & 5758.95 & 475.82 & 6265.89 & 517.70 & 6772.83 & 559.59 \\
\hline & $\%$ & $50.0 \%$ & $4.1 \%$ & $56.0 \%$ & $4.6 \%$ & $62.0 \%$ & $5.1 \%$ & $68.0 \%$ & $5.6 \%$ & $74.0 \%$ & $6.1 \%$ & $80.0 \%$ & $6.6 \%$ \\
\hline \multirow{2}{*}{5} & $\$$ & 4375.43 & 407.72 & 4898.79 & 456.49 & 5422.15 & 505.26 & 5945.51 & 554.03 & 6468.87 & 602.79 & 6992.22 & 651.56 \\
\hline & $\%$ & $51.7 \%$ & $4.8 \%$ & $57.8 \%$ & $5.4 \%$ & $64.0 \%$ & $6.0 \%$ & $70.2 \%$ & $6.5 \%$ & $76.4 \%$ & $7.1 \%$ & $82.6 \%$ & $7.7 \%$ \\
\hline \multirow[t]{2}{*}{6} & $\$$ & 4460.75 & 456.63 & 4994.31 & 511.26 & 5527.88 & 565.87 & 6061.44 & 620.50 & 6595.01 & 675.11 & 7128.57 & 729.74 \\
\hline & $\%$ & $52.7 \%$ & $5.4 \%$ & $59.0 \%$ & $6.0 \%$ & $65.3 \%$ & $6.7 \%$ & $71.6 \%$ & $7.3 \%$ & $77.9 \%$ & $8.0 \%$ & $84.2 \%$ & $8.6 \%$ \\
\hline \multirow[t]{2}{*}{7} & $\$$ & 4514.97 & 497.72 & 5055.02 & 557.25 & 5595.07 & 616.79 & 6135.11 & 676.32 & 6675.16 & 735.86 & 7215.22 & 795.39 \\
\hline & $\%$ & $53.3 \%$ & $5.9 \%$ & $59.7 \%$ & $6.6 \%$ & $66.1 \%$ & $7.3 \%$ & $72.4 \%$ & $8.0 \%$ & $78.8 \%$ & $8.7 \%$ & $85.2 \%$ & $9.4 \%$ \\
\hline \multirow{2}{*}{8} & $\$$ & 4550.25 & 531.96 & 5094.52 & 595.58 & 5638.79 & 659.21 & 6183.06 & 722.84 & 6727.33 & 786.47 & 7271.60 & 850.10 \\
\hline & $\%$ & $53.7 \%$ & $6.3 \%$ & $60.2 \%$ & $7.0 \%$ & $66.6 \%$ & $7.8 \%$ & $73.0 \%$ & $8.5 \%$ & $79.4 \%$ & $9.3 \%$ & $85.9 \%$ & $10.0 \%$ \\
\hline \multirow[t]{2}{*}{9} & $\$$ & 4573.78 & 560.34 & 5120.87 & 627.36 & 5667.95 & 694.39 & 6215.04 & 761.41 & 6762.13 & 828.43 & 7309.21 & 895.46 \\
\hline & $\%$ & $54.0 \%$ & $6.6 \%$ & $60.5 \%$ & $7.4 \%$ & $66.9 \%$ & $8.2 \%$ & $73.4 \%$ & $9.0 \%$ & $79.8 \%$ & $9.8 \%$ & $86.3 \%$ & $10.6 \%$ \\
\hline \multirow{2}{*}{10} & $\$$ & 4589.86 & 583.78 & 5138.87 & 653.61 & 5687.89 & 723.44 & 6236.89 & 793.27 & 6785.90 & 863.10 & 7334.91 & 932.92 \\
\hline & $\%$ & $54.2 \%$ & $6.9 \%$ & $60.7 \%$ & $7.7 \%$ & $67.2 \%$ & $8.5 \%$ & $73.6 \%$ & $9.4 \%$ & $80.1 \%$ & $10.2 \%$ & $86.6 \%$ & $11.0 \%$ \\
\hline
\end{tabular}

Source: research results.

Effects calculated with the combination of the results shown in Tables 6 and 8 .

TABLE 12: Total effect of sugarcane sector expansion on real per capita GDP (in \$ of 2008), assuming that the share of sugarcane in the agriculture remains constant (substitution of pasture and planted forests).

\begin{tabular}{lcccccccccccc}
\hline & \multicolumn{8}{c}{ Expansion of the sugarcane cultivated area (in percentage points of the municipal area) } \\
& 0 & 10 & 20 & 30 & 40 & 50 & 60 & 70 & 80 & 90 & 100 \\
\hline $\begin{array}{l}\text { Contemporaneous } \\
\text { Years forward }\end{array}$ & 2722.37 & 2885.19 & 3048.01 & 3210.82 & 3373.63 & 3536.45 & 3699.27 & 3862.08 & 4024.90 & 4187.72 & 4350.53 \\
1 & & & & & & & & & & & & \\
2 & 4950.85 & 5246.95 & 5543.04 & 5839.14 & 6135.23 & 6431.32 & 6727.42 & 7023.51 & 7319.61 & 7615.70 & 7911.79 \\
3 & 6775.04 & 7180.24 & 7585.43 & 7990.62 & 8395.81 & 8801.01 & 9206.20 & 9611.39 & 10016.59 & 10421.78 & 10826.97 \\
4 & 8268.30 & 8762.79 & 9257.30 & 9751.79 & 10246.29 & 10740.79 & 11235.29 & 11729.79 & 12224.29 & 12718.79 & 13213.28 \\
5 & 9490.64 & 10058.24 & 10625.85 & 11193.45 & 11761.05 & 12328.66 & 12896.26 & 13463.86 & 14031.47 & 14599.07 & 15166.68 \\
6 & 10491.23 & 11118.67 & 11746.12 & 12373.56 & 13001.01 & 13628.45 & 14255.90 & 14883.35 & 15510.79 & 16138.24 & 16765.68 \\
7 & 11310.29 & 11986.72 & 12663.15 & 13339.58 & 14016.02 & 14692.45 & 15368.87 & 16045.31 & 16721.74 & 17398.17 & 18074.60 \\
8 & 11980.76 & 12697.29 & 13413.82 & 14130.35 & 14846.88 & 15563.41 & 16279.94 & 16996.46 & 17712.99 & 18429.52 & 19146.05 \\
9 & 12529.59 & 13278.95 & 14028.30 & 14777.66 & 15527.01 & 16276.36 & 17025.72 & 17775.07 & 18524.42 & 19273.78 & 20023.13 \\
10 & 12978.86 & 13755.08 & 14531.30 & 15307.52 & 16083.75 & 16859.97 & 17636.19 & 18412.42 & 19188.64 & 19964.86 & 20741.08 \\
\hline
\end{tabular}

Source: research results.

Effects calculated with the combination of the results shown in Table 11. 
TABLE 13: Direct and indirect effects of sugarcane sector expansion on real per capita GDP (in \$ of 2008 and as \% of the average municipal per capita GDP in 2008), assuming that there is no replacement of any other farmland activity.

\begin{tabular}{|c|c|c|c|c|c|c|c|c|c|c|c|c|c|}
\hline & & \multicolumn{12}{|c|}{ Expansion of the sugarcane cultivated area (in percentage points of the municipal area) } \\
\hline & & \multicolumn{2}{|c|}{0} & \multicolumn{2}{|c|}{20} & \multicolumn{2}{|c|}{40} & \multicolumn{2}{|c|}{60} & \multicolumn{2}{|c|}{80} & \multicolumn{2}{|c|}{100} \\
\hline & & Direct & Indirect & Direct & Indirect & Direct & Indirect & Direct & Indirect & Direct & Indirect & Direct & Indirect \\
\hline \multirow{2}{*}{ Contemporaneous } & $\$$ & 1901.44 & 54.73 & 2052.51 & 59.08 & 2203.58 & 63.43 & 2354.66 & 67.78 & 2505.73 & 72.12 & 2656.80 & 76.47 \\
\hline & $\%$ & $22.5 \%$ & $0.6 \%$ & $24.2 \%$ & $0.7 \%$ & $26.0 \%$ & $0.7 \%$ & $27.8 \%$ & $0.8 \%$ & $29.6 \%$ & $0.9 \%$ & $31.4 \%$ & $0.9 \%$ \\
\hline \multicolumn{14}{|l|}{ Years forward } \\
\hline \multirow{2}{*}{1} & $\$$ & 2997.68 & 130.21 & 3235.85 & 140.56 & 3474.02 & 150.90 & 3712.19 & 161.25 & 3950.36 & 171.60 & 4188.53 & 181.94 \\
\hline & $\%$ & $35.4 \%$ & $1.5 \%$ & $38.2 \%$ & $1.7 \%$ & $41.0 \%$ & $1.8 \%$ & $43.8 \%$ & $1.9 \%$ & $46.6 \%$ & $2.0 \%$ & $49.5 \%$ & $2.1 \%$ \\
\hline \multirow{2}{*}{2} & $\$$ & 3636.20 & 209.26 & 3925.09 & 225.88 & 4213.99 & 242.51 & 4502.89 & 259.13 & 4791.79 & 275.76 & 5080.69 & 292.38 \\
\hline & $\%$ & $42.9 \%$ & $2.5 \%$ & $46.3 \%$ & $2.7 \%$ & $49.8 \%$ & $2.9 \%$ & $53.2 \%$ & $3.1 \%$ & $56.6 \%$ & $3.3 \%$ & $60.0 \%$ & $3.5 \%$ \\
\hline \multirow{2}{*}{3} & $\$$ & 4012.74 & 283.70 & 4331.56 & 306.25 & 4650.38 & 328.79 & 4969.20 & 351.32 & 5288.01 & 373.86 & 5606.83 & 396.40 \\
\hline & $\%$ & $47.4 \%$ & $3.3 \%$ & $51.1 \%$ & $3.6 \%$ & $54.9 \%$ & $3.9 \%$ & $58.7 \%$ & $4.1 \%$ & $62.4 \%$ & $4.4 \%$ & $66.2 \%$ & $4.7 \%$ \\
\hline \multirow{2}{*}{4} & $\$$ & 4238.14 & 350.17 & 4574.86 & 377.99 & 4911.58 & 405.81 & 5248.31 & 433.63 & 5585.03 & 461.45 & 5921.76 & 489.27 \\
\hline & $\%$ & $50.0 \%$ & $4.1 \%$ & $54.0 \%$ & $4.5 \%$ & $58.0 \%$ & $4.8 \%$ & $62.0 \%$ & $5.1 \%$ & $65.9 \%$ & $5.4 \%$ & $69.9 \%$ & $5.8 \%$ \\
\hline \multirow{2}{*}{5} & $\$$ & 4375.43 & 407.72 & 4723.06 & 440.11 & 5070.69 & 472.51 & 5418.33 & 504.90 & 5765.96 & 537.30 & 6113.59 & 569.69 \\
\hline & $\%$ & $51.7 \%$ & $4.8 \%$ & $55.8 \%$ & $5.2 \%$ & $59.9 \%$ & $5.6 \%$ & $64.0 \%$ & $6.0 \%$ & $68.1 \%$ & $6.3 \%$ & $72.2 \%$ & $6.7 \%$ \\
\hline \multirow{2}{*}{6} & $\$$ & 4460.75 & 456.63 & 4815.16 & 492.92 & 5169.57 & 529.20 & 5523.98 & 565.48 & 5878.39 & 601.76 & 6232.80 & 638.04 \\
\hline & $\%$ & $52.7 \%$ & $5.4 \%$ & $56.9 \%$ & $5.8 \%$ & $61.0 \%$ & $6.2 \%$ & $65.2 \%$ & $6.7 \%$ & $69.4 \%$ & $7.1 \%$ & $73.6 \%$ & $7.5 \%$ \\
\hline \multirow{2}{*}{7} & $\$$ & 4514.97 & 497.72 & 4873.68 & 537.26 & 5232.40 & 576.81 & 5591.12 & 616.36 & 5949.84 & 655.90 & 6308.56 & 695.44 \\
\hline & $\%$ & $53.3 \%$ & $5.9 \%$ & $57.5 \%$ & $6.3 \%$ & $61.8 \%$ & $6.8 \%$ & $66.0 \%$ & $7.3 \%$ & $70.3 \%$ & $7.7 \%$ & $74.5 \%$ & $8.2 \%$ \\
\hline \multirow{2}{*}{8} & $\$$ & 4550.25 & 531.96 & 4911.77 & 574.22 & 5273.30 & 616.49 & 5634.81 & 658.75 & 5996.34 & 701.02 & 6357.86 & 743.28 \\
\hline & $\%$ & $53.7 \%$ & $6.3 \%$ & $58.0 \%$ & $6.8 \%$ & $62.3 \%$ & $7.3 \%$ & $66.5 \%$ & $7.8 \%$ & $70.8 \%$ & $8.3 \%$ & $75.1 \%$ & $8.8 \%$ \\
\hline \multirow{2}{*}{9} & $\$$ & 4573.78 & 560.34 & 4937.17 & 604.86 & 5300.57 & 649.38 & 5663.96 & 693.90 & 6027.35 & 738.42 & 6390.74 & 782.93 \\
\hline & $\%$ & $54.0 \%$ & $6.6 \%$ & $58.3 \%$ & $7.1 \%$ & $62.6 \%$ & $7.7 \%$ & $66.9 \%$ & $8.2 \%$ & $71.2 \%$ & $8.7 \%$ & $75.5 \%$ & $9.2 \%$ \\
\hline \multirow{2}{*}{10} & $\$$ & 4589.86 & 583.78 & 4954.54 & 630.16 & 5319.20 & 676.55 & 5683.87 & 722.93 & 6048.55 & 769.31 & 6413.21 & 815.69 \\
\hline & $\%$ & $54.2 \%$ & $6.9 \%$ & $58.5 \%$ & $7.4 \%$ & $62.8 \%$ & $8.0 \%$ & $67.1 \%$ & $8.5 \%$ & $71.4 \%$ & $9.1 \%$ & $75.7 \%$ & $9.6 \%$ \\
\hline
\end{tabular}

Source: research results.

Effects calculated with the combination of the results shown in Tables 5 and 8.

TABLE 14: Total effect of sugarcane sector expansion on real per capita GDP (in \$ of 2008), assuming that there is no replacement of any other farmland activity.

\begin{tabular}{|c|c|c|c|c|c|c|c|c|c|c|c|}
\hline & \multicolumn{11}{|c|}{ Expansion of the sugarcane cultivated area (in percentage points of the municipal area) } \\
\hline & 0 & 10 & 20 & 30 & 40 & 50 & 60 & 70 & 80 & 90 & 100 \\
\hline Contemporaneous & 2722.37 & 2830.52 & 2938.67 & 3046.81 & 3154.96 & 3263.11 & 3371.26 & 3479.40 & 3587.55 & 3695.70 & 3803.85 \\
\hline \multicolumn{12}{|l|}{ Years forward } \\
\hline 1 & 4950.85 & 5147.53 & 5344.20 & 5540.88 & 5737.55 & 5934.23 & 6130.90 & 6327.58 & 6524.26 & 6720.93 & 6917.61 \\
\hline 2 & 6775.04 & 7044.19 & 7313.33 & 7582.47 & 7851.61 & 8120.75 & 8389.90 & 8659.04 & 8928.19 & 9197.33 & 9466.47 \\
\hline 3 & 8268.30 & 8596.75 & 8925.22 & 9253.68 & 9582.14 & 9910.61 & 10239.07 & 10567.53 & 10895.99 & 11224.45 & 11552.92 \\
\hline 4 & 9490.64 & 9867.66 & 10244.68 & 10621.70 & 10998.72 & 11375.74 & 11752.77 & 12129.79 & 12506.80 & 12883.83 & 13260.85 \\
\hline 5 & 10491.23 & 10908.00 & 11324.77 & 11741.54 & 12158.31 & 12575.08 & 12991.85 & 13408.62 & 13825.39 & 14242.15 & 14658.92 \\
\hline 6 & 11310.29 & 11759.60 & 12208.91 & 12658.21 & 13107.52 & 13556.83 & 14006.14 & 14455.44 & 14904.75 & 15354.06 & 15803.37 \\
\hline 7 & 11980.76 & 12456.70 & 12932.64 & 13408.58 & 13884.53 & 14360.47 & 14836.42 & 15312.36 & 15788.30 & 16264.24 & 16740.18 \\
\hline 8 & 12529.59 & 13027.34 & 13525.08 & 14022.83 & 14520.57 & 15018.32 & 15516.06 & 16013.81 & 16511.55 & 17009.30 & 17507.04 \\
\hline 9 & 12978.86 & 13494.45 & 14010.04 & 14525.63 & 15041.22 & 15556.82 & 16072.41 & 16588.00 & 17103.60 & 17619.19 & 18134.78 \\
\hline 10 & 13346.62 & 13876.82 & 14407.02 & 14937.22 & 15467.42 & 15997.62 & 16527.83 & 17058.03 & 17588.23 & 18118.43 & 18648.63 \\
\hline
\end{tabular}

Source: research results.

Effects calculated with the combination of the results shown in Table 13. 
Between 2000 and 2008, the number of towns with operational plants and/or distilleries increased by 34 in São Paulo State. The area given over to sugarcane grew by the equivalent to $8.3 \%$ of state territory. As the state's agriculture grew by an area equivalent to $7.4 \%$, sugarcane can be said to have substituted other crops in less than 1\% of São Paulo State's area. Moreover, as the area occupied by farming remained practically the same throughout the period, most sugarcane expansion was found to have taken place on land previously used for pasture and planted forests.

As operations began in industrial units of the sugarcane sector in 34 new towns, the total impact on São Paulo State can be said to be positive if the expansion of sugarcane took place exclusively as a substitution for other crops in an area equivalent to up to $3.83 \%$ of state territory. (The results of the estimated model show that making a sugarcane sector unit operational in one town has a positive impact if the expansion of the sugarcane associated with it does not exclusively substitute other crops up to a proportion of $72.68 \%$ of the municipal territory. As, during the period under study, this occurred in 34 of the 645 towns in the state, the threshold for this expansion to have a positive impact in São Paulo State is $34 \times 72.68 \% / 645=3.83 \%$.) Furthermore, as the total positive effect is significantly higher when the expansion of sugarcane takes place on pasture land and in planted forests, the expansion of the sugarcane sector between 2000 and 2008 can be said to have had a positive impact on the level of real per capita GDP in the towns in São Paulo State.

This paper is a first effort towards a better comprehension of the socioeconomic impacts of the sugarcane sector. In future works, the analysis will be extended to other Brazilian states where the expansion of sugarcane sector was also significant. Then, results will be checked for robustness with the utilization of alternative spatial weighting matrixes, and counterfactuals will estimate the hypothetical distribution of municipal per capita GDP under the assumption that sugarcane sector expansion has not happened.

\section{References}

[1] Instituto Brasileiro de Geografia e Estatística-IBGE, Banco de dados agregados: sistema IBGE de recuperação automáticaSIDRA, http://www.sidra.ibge.gov.br/.

[2] A. M. Nassar, B. F. T. Rudorff, L. B. Antoniazzi, D. A. de Aguiar, M. R. P. Bacchi, and M. Adami, "Prospects of the sugarcane expansion in Brazil: impacts on direct and indirect land use changes," in Contributions To Climate Change Mitigation and the Environment, P. Zuurbier and J. van der Vooren, Eds., pp. 63-93, Wageningen Academic Publishers, Wageningen, The Netherlands, 2008.

[3] A. Deaton and J. Muellbauer, Economics and Consumer Behavior, Cambridge University Press, New York, NY, USA, 2009.

[4] R. Silva, "Setor sucroalcooleiro no Estado de São Paulo: mensurando impactos sócio-econômicos," in Workshop do Observatario do Setor Sucroalcooleiro, FEA-RP, Ribeirão Preto, Brazil, 2008.

[5] A. Walter, P. Dolzan, O. Quilodrán et al., "A sustainability analysis of the Brazilian ethanol," in Biocombustivel Brasileiro: Uma Análise de Sustentabilidade, UNICAMP, Campinas, Brazil, 2008.
[6] G. Spavorek, A. Barreto, G. Berndes, S. Martins, and R. Maule, "Environmental, land-use and economic implications of Brazilian sugarcane expansion 1996-2006," Mitigation and Adaptation Strategies For Global Change, vol. 14, no. 3, pp. 285298, 2009.

[7] A. Deuss, "Did sugarcane expansion lead to GDP growth in São Paulo state? An analysis at municipal level using propensity score-based estimators," 2009, https://editorialexpress.com/cgibin/conference/download.cgi?db_name=res_phd_2010\&paper_ id $=174$.

[8] J. G. de Oliveira, Indicadores Sócio-Econômicos em Estados Produtores de Cana-de-Açúcar: Análise Comparativa Entre Municípios [Doutorado em Planejamento de Sistemas Energéticos], Faculdade de Engenharia Mecânica, Universidade Estadual de Campinas, Campinas, Brazil, 2011.

[9] A. L. S. Chagas, R. Toneto Jr., and C. R. Azzoni, "The expansion of sugar cane cultivation and its impacts on municipal revenues," in Energy, Bio Fuels and Development: Comparing Brazil and the United States, E. Amann, W. Baer, and D. V. Coes, Eds., Routledge, New York, NY, USA, 2010.

[10] A. L. S. Chagas, R. Toneto Jr., and C. R. Azzoni, "Avaliando os impactos da produção de cana-de-açúcar sobre indicadores sociais de regiões produtoras por meio de propensity score matching espacial," in Congresso da Sociedade Brasileira de Economia, Administração e Sociologia Rural, vol. 48, SOBERB, Brasilia, Brazil, 2010.

[11] A. L. S. Chagas, R. Toneto Jr., and C. R. Azzoni, "Sugar cane, land use and regional development," Texto para Discussão 009/2011, Universidade Federal de Juiz de Fora, Juiz de Fora, Brazil, 2011, Programa de Pós-Graduação em Economia Aplicada.

[12] R. P. de Barros, M. de Carvalho, S. Franco, and R. Mendonça, Acesso ao trabalho e produtividade no Brasil: implicações para crescimento, pobreza e desigualdade, IPEA, Rio de Janeiro, Brazil, 2004.

[13] Fundação Sistema Estadual de Análise de Dados-SEADE. Informações dos municípios paulistas, http://www.seade.gov .br/produtos/imp/.

[14] Instituto de Pesquisa Econômica Aplicada-IPEA, Ipeadata, http://www.ipeadata.gov.br/.

[15] Instituto de Economia Agrícola-IEA. Banco de dados: Área e produção, http://www.iea.sp.gov.br/out/index.php.

[16] M. Kukenova and J. A. Monteiro, "Spatial dynamic panel model and system GMM: a Monte Carlo investigation,” MPRA Paper 14319, Munich Personal RePEc Archive, 2009.

[17] R. K. Pace and R. Barry, "Sparse spatial autoregressions," Statistics and Probability Letters, vol. 33, no. 3, pp. 291-297, 1997.

[18] J. P. Elhorst, "Dynamic spatial panels: Models, methods, and inferences," Journal of Geographical Systems, vol. 14, no. 1, pp. $5-28,2012$.

[19] J. P. Elhorst, "Dynamic models in space and time," Geographical Analysis, vol. 33, no. 2, pp. 119-140, 2001.

[20] O. Parent and J. P. LeSage, "A space-time filter for panel data models containing random effects," Computational Statistics and Data Analysis, vol. 55, no. 1, pp. 475-490, 2011.

[21] N. Debarsy, C. Ertur, and J. P. LeSage, "Interpreting dynamic space-time panel data models," Statistical Methodology, vol. 9, no. 1-2, pp. 158-171, 2012.

[22] M. Arellano and S. R. Bond, "Some tests specification for panel data: Monte Carlo evidence and application to employment equations," Review of Economic Studies, vol. 58, pp. 277-297, 1991. 
[23] L. F. Satolo, Impactos socioeconômicos da expansão do setor sucroenergético: uma análise espacial dinâmica sobre o bemestar social no Estado de São Paulo (2000-2008) [Doutorado em Economia Aplicada], Escola Superior de Agricultura "Luiz de Queiroz”, Universidade de São Paulo, Piracicaba, Brazil, 2012. 


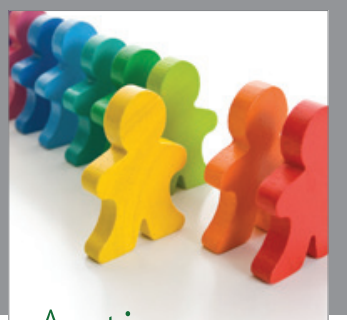

Autism

Research and Treatment
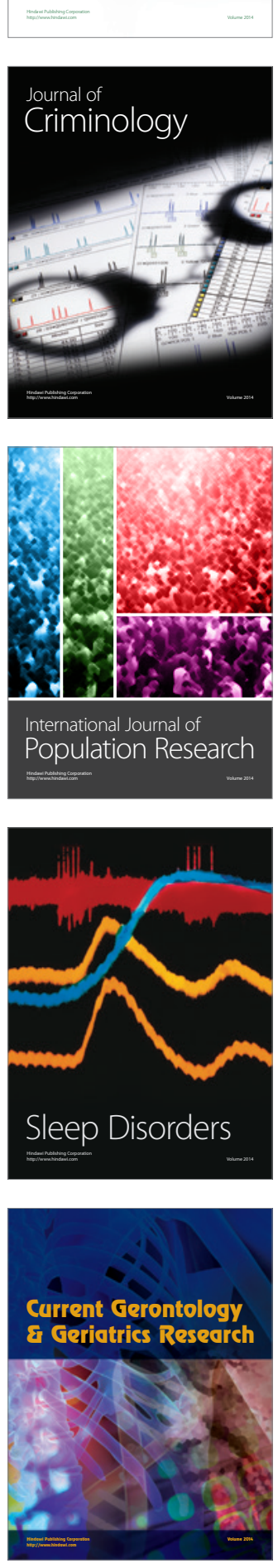
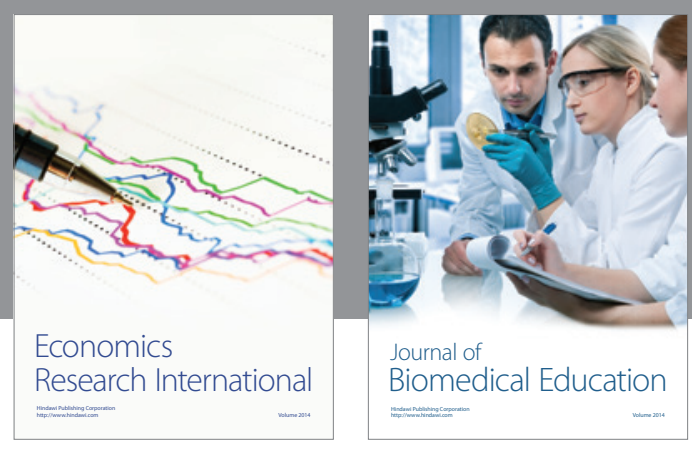

Journal of

Biomedical Education

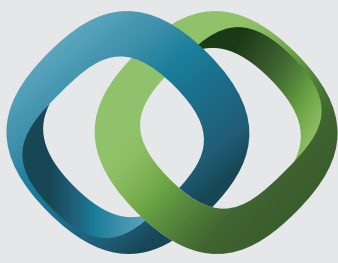

\section{Hindawi}

Submit your manuscripts at

http://www.hindawi.com
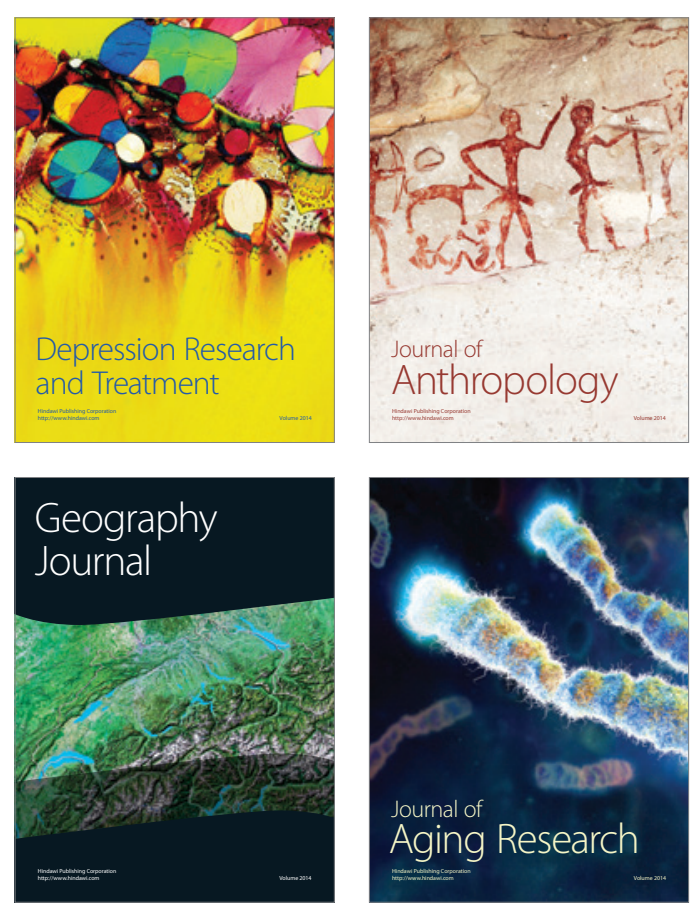

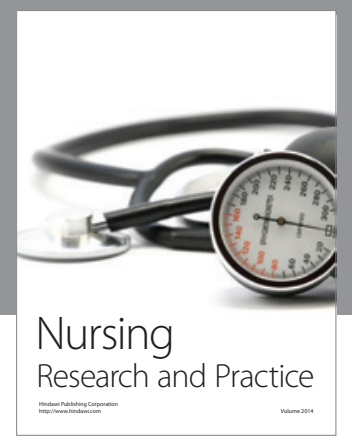

Nursing

Research and Practice

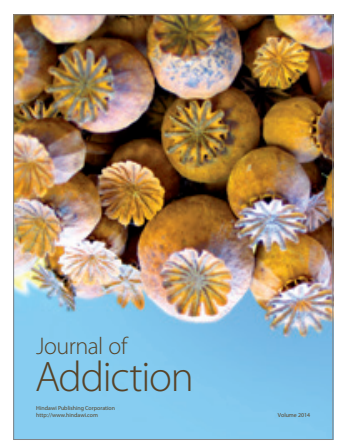

Child Development

Research

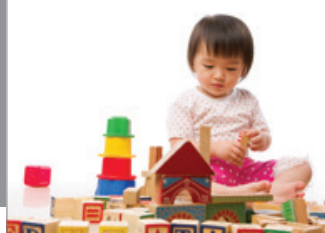

迥
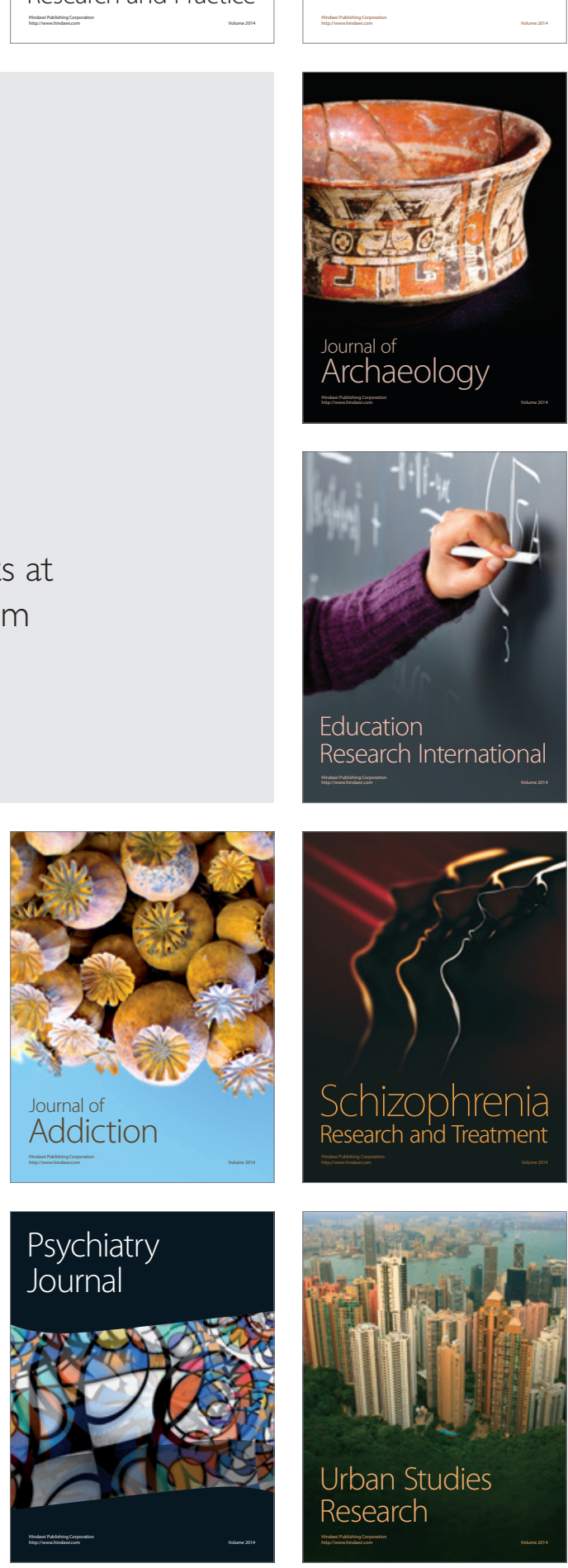